\title{
Synaptic Plasticity in vitro: Cell Culture of Identified Aplysia Neurons Mediating Short-Term Habituation and Sensitization
}

\author{
Stephen G. Rayport and Samuel Schacher \\ Center for Neurobiology and Behavior, Departments of Anatomy and Cell Biology, and of Psychiatry, \\ Columbia University College of Physicians and Surgeons, and \\ The New York State Psychiatric Institute, New York, New York 10032
}

\begin{abstract}
The gill withdrawal reflex of the marine mollusk, Aplysia californica, shows habituation and sensitization, two simple forms of learning. In order to extend the cellular studies on synaptic plasticity underlying the changes in the reflex behavior, and to explore further the development of synaptic plasticity during synapse formation, we have sought to establish the neural circuit of the gill withdrawal reflex in vitro. We report here the reconstruction of the elementary gill withdrawal circuit in cell culture and find that the cells show short-term homosynaptic depression and heterosynaptic facilitation, the cellular mechanisms of habituation and sensitization, respectively.
\end{abstract}

The gill withdrawal reflex of the marine snail, Aplysia californica, is a simple defensive reflex mediated by a population of about 24 sensory cells, six motor cells, and several interneurons (Kandel, 1979). The reflex undergoes two forms of nonassociative learning, habituation and sensitization, as well as classical conditioning (Carew et al., 1983; Kandel and Schwartz, 1982). The elementary cellular substrate underlying these forms of learning consists of sensory neurons that monosynaptically connect with a motor cell and a facilitatory neuron that synapses onto the presynaptic terminals of the sensory neurons (Bailey et al., 1979, 1981). Analysis of these forms of learning at the cellular level indicates that stimulus experience modulates transmitter release from the terminals of the sensory neurons (Hawkins et al., 1983; Klein et al., 1980). Habituation of the reflex is mediated by homosynaptic depression, a decrease in transmitter release from the sensory neuron presynaptic terminals with repeated stimulation (Castellucci and Kandel, 1974). Sensitization is based on heterosynaptic (presynaptic) facilitation, an increase in transmitter release from sensory neurons due in part to a reduction in a $\mathrm{K}^{+}$current, and a consequent increased $\mathrm{Ca}^{2+}$ influx (Castellucci and Kandel, 1976; Klein and Kandel, 1978; Klein et al., 1982). Sensitization in the intact nervous system is mediated either by activity in a number of facilitator neurons, some of which are identified, or by the exogenous facilitatory neurotransmitters, namely, serotonin $(5-\mathrm{HT})$ or the small mol-

\footnotetext{
Received Mar. 22, 1985; revised May 28, 1985; accepted June 18, 1985.

This work was supported by National Science Foundation Grant 15948 to S.S. and National Institutes of Health Grant GM 32099, which supports the mariculture facility at the Marine Biological Laboratory. We wish to thank R. Woolley and L. Katz for their technical assistance, T. Capo and S. Perritt for raising the animals used in this study, and $\mathrm{H}$. Ayers for typing the manuscript. We also thank Drs. E. Kandel, V. Castellucci, and M. Klein for their comments on earlier drafts of the manuscript.

Correspondence should be addressed to Dr. Schacher, Center for Neurobiology and Behavior, The New York State Psychiatric Institute, Research Annex, 722 West 168th Street, New York, NY 10032.

Copyright (C) 1986 Society for Neuroscience $0270-6474 / 86 / 030759-05 \$ 02.00 / 0$
}

luscan cardiac peptides (Abrams et al., 1984; Brunelli et al., 1976; Hawkins et al., 1981b).

To gain direct access to the synapses mediating the learning exhibited by this reflex, and to enable us to explore the developmental processes involved in the acquisition of plastic propcrtics by newly formed synapses, we have sought to establish the elementary gill withdrawal circuit in vitro. Here we describe the cell culture of dissociated sensory and motor neurons that mediate the reflex and the culture of a modulatory cell, the serotonergic metacerebral cell (MCC), which simulates the in vivo facilitating pathway. The MCC was used as a facilitator ccll for two reasons. First, it can be identified and easily isolated from the cerebral ganglion (Schacher, 1985). Second, the MCC produces a 5-HT-mediated modulation of muscle activity via an increase in cAMP (Weiss et al., 1978, 1979) that is comparable to facilitation at the LE-L7 connections (Kandel and Schwartz, 1982). The three cells form the characteristic synaptic connections after $5 \mathrm{~d}$ in culture, and show homosynaptic depression and heterosynaptic facilitation. Bath application of 5-HT also produces facilitation of the sensorimotor connection.

\section{Materials and Methods}

\section{Cell culture preparations}

The isolation and maintenance of Aplysia neurons in cell culture have been described (Schacher, 1985; Schacher and Proshansky, 1983). Abdominal and cerebral ganglia from 1-3 gm animals raised in the laboratory (Kriegstein, 1977; Kriegstein et al., 1974) were bathed in proteolytic enzyme for $2 \mathrm{hr}$, and adult abdominal ganglia excised from 100-150 gm animals (Sea Life Supply, Sand City, CA) were exposed to the same proteolytic digest for $2.5 \mathrm{hr}$. The ganglia were pinned in Sylgard- (Dow Corning, Midland, MI) coated dishes and desheathed. The gill motor cell L7 was isolated from the juvenile abdominal ganglion, the MCC was isolated from the juvenile cerebral ganglion, and the LE mechanosensory cells were isolated from the adult abdominal ganglion. Cells were identified by size, position, and pigmentation, and axon distribution during removal from the ganglion. The isolated cells were transferred to polylysine-coated culture dishes with medium containing Aplysia hemolymph and L15 (Flow Laboratories, McLean, VA), with salts added to adjust the medium to marine saline conditions. The cultures were maintained for $5 \mathrm{~d}$ at $18^{\circ} \mathrm{C}$ with medium changes on alternate days.

\section{Electrophysiology}

Using standard electrophysiological technique, sensory, motor, and metacerebral cells were impaled simultaneously with single-barreled electrodes filled with $2.5 \mathrm{M} \mathrm{KCl}$. Motor cells were hyperpolarized $50 \mathrm{mV}$ bclow thcir resting potential by intracellular current injection, in order to block spontaneous and stimulus-evoked activity. Sensory neurons were then stimulated with short depolarizing pulses every $20 \mathrm{sec}$. After five stimuli, either the MCC was fired at $3-5 \mathrm{~Hz}$ for $15 \mathrm{sec}$, using a long 


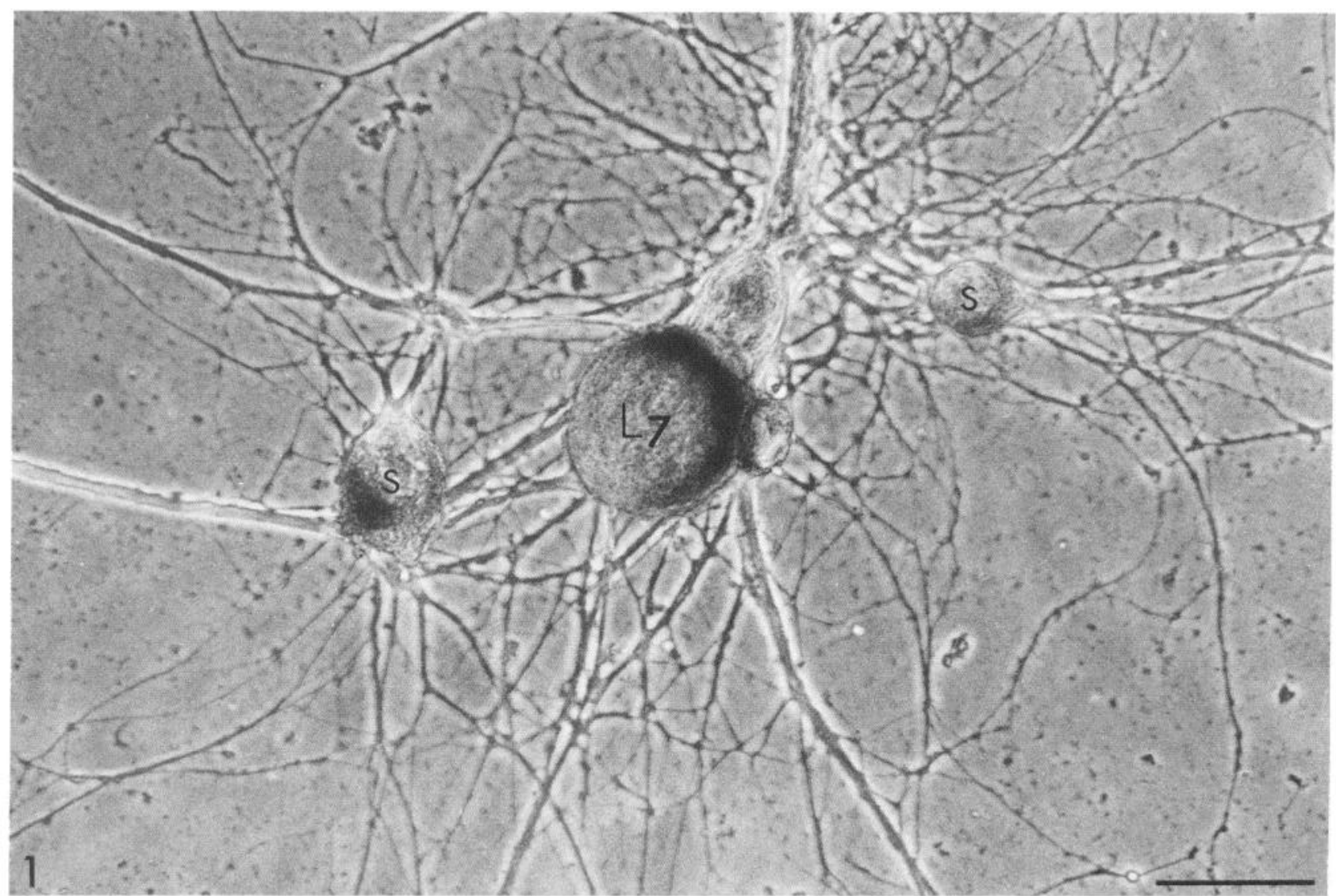

Figure 1. Neurons mediating gill withdrawal in vitro. The circuit consists of two LE sensory neurons and one gill motor cell L7 after $5 \mathrm{~d}$ in culture. $S=$ LE sensory cell; $L 7=$ motor cell. Calibration, $100 \mu \mathrm{M}$.

depolarizing step, or 5-HT (Sigma, St. Louis, MO) was added to the bath to a final concentration of $2 \times 10^{-6} \mathrm{M}$. The five subsequent stimuli were recorded to measure facilitation. The cultures were perfused continuously with buffered artificial seawater $(\mathrm{pH} \mathrm{7.6)}$ throughout the recordings, except during the addition of 5-HT. In some cultures, seawater containing $50 \mathrm{~mm}$ tetraethylammonium (TEA) was used to enhance measurements of widths of action potentials evoked in sensory neurons before and after MCC stimulation or 5-HT application.

\section{Results}

Elementary gill withdrawal circuit shows homosynaptic depression and 5-HT-induced facilitation

The elementary circuit established in cell culture consisted of one or more LE sensory cells, the major gill motor cell L7, and, in some cultures, the serotonergic MCC, which we used as a facilitator neuron. After $5 \mathrm{~d}$ in culture, the cells had formed an extensive neuritic network (Figs. 1 and $4 A$ ), and in $80 \%$ of the cultures (11 of 14), there were robust connections between LE and L7, with an average postsynaptic potential (PSP) amplitude of $8.0 \pm 2.5 \mathrm{mV}(n=11)$, latency of $3-5 \mathrm{msec}$, and a configuration characteristic of the in vivo connection. The LE-L7 connection was unidirectional, and there was no detectable electrical coupling between the cells.

As in studies in both the intact animal and the isolated nervous system, a single spike elicited in an LE sensory cell resulted in an excitatory PSP in L7 (Figs. $2 A_{1}$ and $4 B_{1}$ ). Repeated stimuli every $20 \mathrm{sec}-\mathrm{a}$ rate that produces habituation in the intact animal-led to a gradual decrease in the PSP to $30 \%$ of the initial value, paralleling homosynaptic depression in vivo (Figs. 2 and $4 B$ ). If allowed to rest for $10 \mathrm{~min}$, the strength of the connection returned to $80 \%$ of its initial level (not shown). Rapid facilitation occurred when, after the fifth stimulus, 5-HT was added to the bath to a final concentration of $2 \times 10^{-6} \mathrm{M}$. As in in vivo, 5 -HT produced a small $(1-5 \mathrm{mV})$ decreased conductance depolarization in the sensory neurons [see also Belardetti et al. (1985) on 5-HT effects on sensory neurons in vitro] and slow depolarization $\left(2-6 \mathrm{mV}\right.$ ) in L7 (Fig. $2 A_{1}$ ). By the seventh stimulus, the PSP size increased by nearly $300 \%$ (Fig. $2 B$ ). To rule out the effects of depolarization alone in enhancing transmitter release, current was injected into sensory neurons to produce a 1-5 mV depolarization. This had little or no effect on PSP amplitude (data not shown). Serotonin also produced a change in the time course of the PSP, an increase in rise time, and slower decay (compare stimuli 1 and 5 with stimulus 7 in Fig. $2 \mathrm{~A}_{2}$ ). These 5-HT effects are similar to those observed in vivo (Klein et al., 1980, Figs. 25 and 26) and are consistent with the 5-HT-induced effects on the shape of the sensory neuron action potential. In vitro 5-HT application led to spike broadening of $10 \%$ in normal seawater (Fig. $3, n=3$ ) and $50 \%$ in seawater containing $50 \mathrm{~mm}$ TEA $(n=3)$. Such changes in the action potential duration are capable of producing significant increases in transmitter release from the sensory neurons both in vivo and in vitro (Hochner et al., 1985; Klein et al., 1980).

Three-cell gill withdrawal circuit in vitro shows homosynaptic depression and heterosynaptic facilitation

To further compare the culture system to the in vivo circuit, we cultured sensory and motor cells with the serotonergic MCC $(n=5)$ and examined the effects of MCC spike activity on LEL7 connections (Fig. 4). Repeated LE cell action potentials every 
$A_{1}$
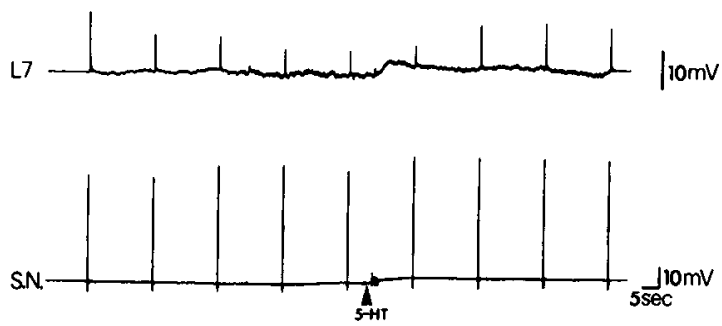

$A_{2}$
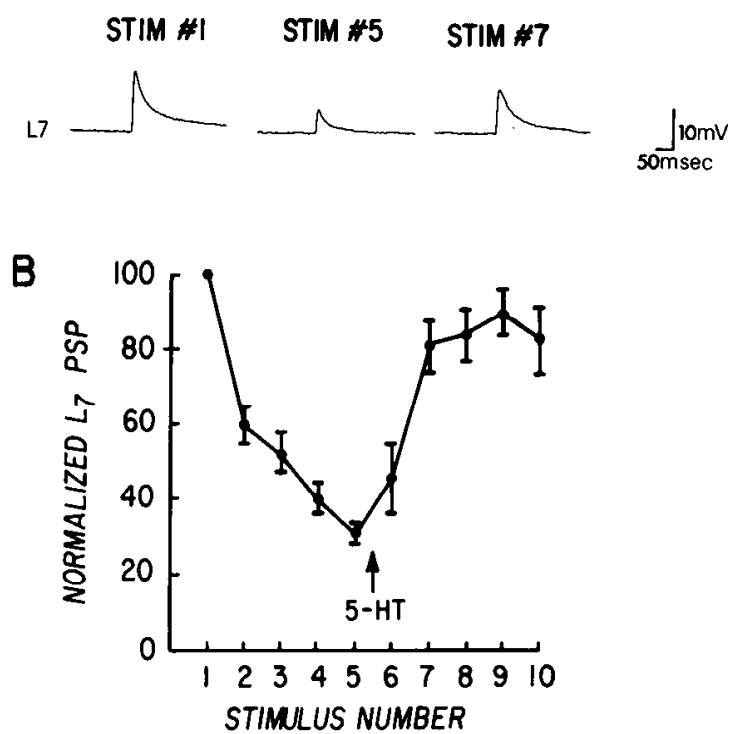

Figure 2. Sensorimotor circuit shows homosynaptic depression and 5-HT-induced facilitation. $A_{l}$, In a slow sweep record, sensory and motor cells were simultaneously impaled with single-barreled electrodes. The motor cell (L7) was hyperpolarized $50 \mathrm{mV}$ below rest. The sensory neuron was fired with a brief depolarizing pulse every $20 \mathrm{sec}$ (lower trace). By the fifth stimulus, the PSP amplitude in L7 (upper trace) was depressed. Between the fourth and fifth stimuli, the perfusion was halted, which occasionally produced a small $(0.5-1 \mathrm{mV})$ depolarization. After the fifth stimulus, 5-HT was applied (arrowhead) to a final concentration of $2 \times 10^{-6} \mathrm{M}$. Within a few seconds, both the sensory neuron and motor cell showed a small, slow depolarization. The initial depolarization in the motor cell typically was followed by a small repolarization, which then plateaued and remained at that level for the duration of the 5-HT exposure. By the seventh stimulus, the PSP amplitude was increased about 3-fold from the depressed level. $A$, Fast sweep record of the EPSP in L7 for the first, fifth, and seventh stimuli from the series shown in $A_{l} . B$, Summary of homosynaptic depression and 5-HT facilitation from five experiments. The LE-L7 PSPs were normalized relative to the initial PSP in each experiment. Points are means and SEM.

20 sec evoked PSPs in L7 and produced synaptic depression (Fig. $4 B$ ) with kinetics similar to that observed for the two-cell circuit (Fig. $2 B$ ). Interposing repeated MCC spikes at $3-5 \mathrm{~Hz}$ for $15 \mathrm{sec}$ between the fifth and sixth stimuli produced a $200 \%$ enhancement of the PSP (Fig. 4B), replicating heterosynaptic facilitation in vivo. MCC stimulation also produced a small depolarization (1-2 mV) in the sensory and motor cells, the typical responses observed with exogenous 5-HT application (see Fig. $2 A$ ) and facilitator neuron activity in the intact nervous system (Hawkins et al., 1981a).

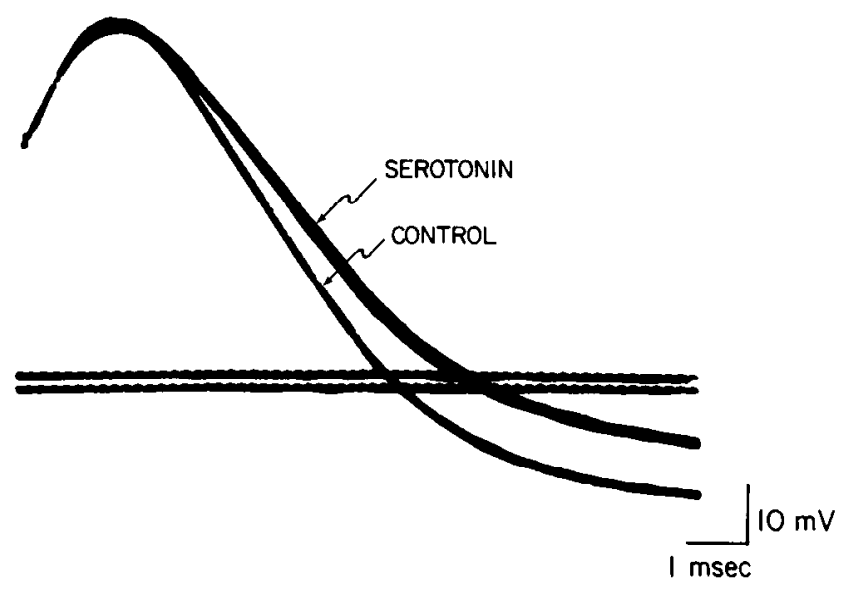

Figure 3. Spike broadening with 5-HT application in normal seawater. 5 -HT, $2 \times 10^{-6} \mathrm{M}$, led to a notable increase in spike width as well as a small depolarization from baseline.

\section{Discussion}

For the first time, a neural circuit with a known behavioral role has been established in cell culture. Although modulation of the gill withdrawal reflex in the intact animal involves other interneurons (Hawkins et al., 1981a), an elementary three-cell circuit consisting of a sensory neuron, a motor neuron, and a modulatory neuron, is both necessary and sufficient to show shortterm homosynaptic depression and heterosynaptic facilitation, the cellular mechanisms of habituation and sensitization. These plastic properties, especially homosynaptic depression, are specific to the LE-L7 circuit. Other Aplysia cells that form chemical connections in vitro show stable PSP amplitudes, with stimulation rates that depress the LE-L7 connection (Camardo et al., 1983; Schacher et al., 1985). Heterosynaptic facilitation of LE-L7 connections can also be produced by other cells. Preliminary experiments with cultures in which the serotonergic MCC was replaced with the identified abdominal ganglion facilitator L29 (Hawkins et al., 1981b) also showed heterosynaptic facilitation (Hawkins and Schacher, unpublished observations). Further, the circuit may be capable of long-term facilitation. Synaptic transmission between LE and L 7 can be enhanced in cultures with spontaneously active MCCs or following repeated applications of exogenous 5-HT (Montarolo et al., 1985; Rayport and Schacher, 1984). The elementary circuit may, in future work, be explored for the capacity to show activity-dependent facilitation, the cellular mechanism mediating classical conditioning of this reflex (Hawkins et al., 1983). For studying both nonassociative and associative mechanisms, the exposed processes and visualizable terminals of the circuit in vitro offer the possibility of examining subcellular mechanisms of synaptic plasticity in the previously inaccessible synaptic region itself (Belardetti et al., 1985).

Although the MCC does not interact with abdominal ganglion cells in vivo, activity in the MCC evokes small 5-HT-like depolarizing responses of long latency and duration in both the sensory and motor cells and facilitates sensorimotor connections. We do not know as yet whether these MCC effects are the result of the formation of synapses by MCC with sensory or motor cells or are caused by an activity-dependent release of 5-HT that diffuses to neighboring sensory and motor structures. The release of transmitter from neurons grown in culture, in the absence of target cells, has been recently demonstrated for spinal cord and ciliary ganglion cells (Hume et al., 1983; Young and Poo, 1983) and individual neuropeptidergic buccal cells of $A p l y$ sia (Weiss et al., 1985). Thus, local transmitter release from 

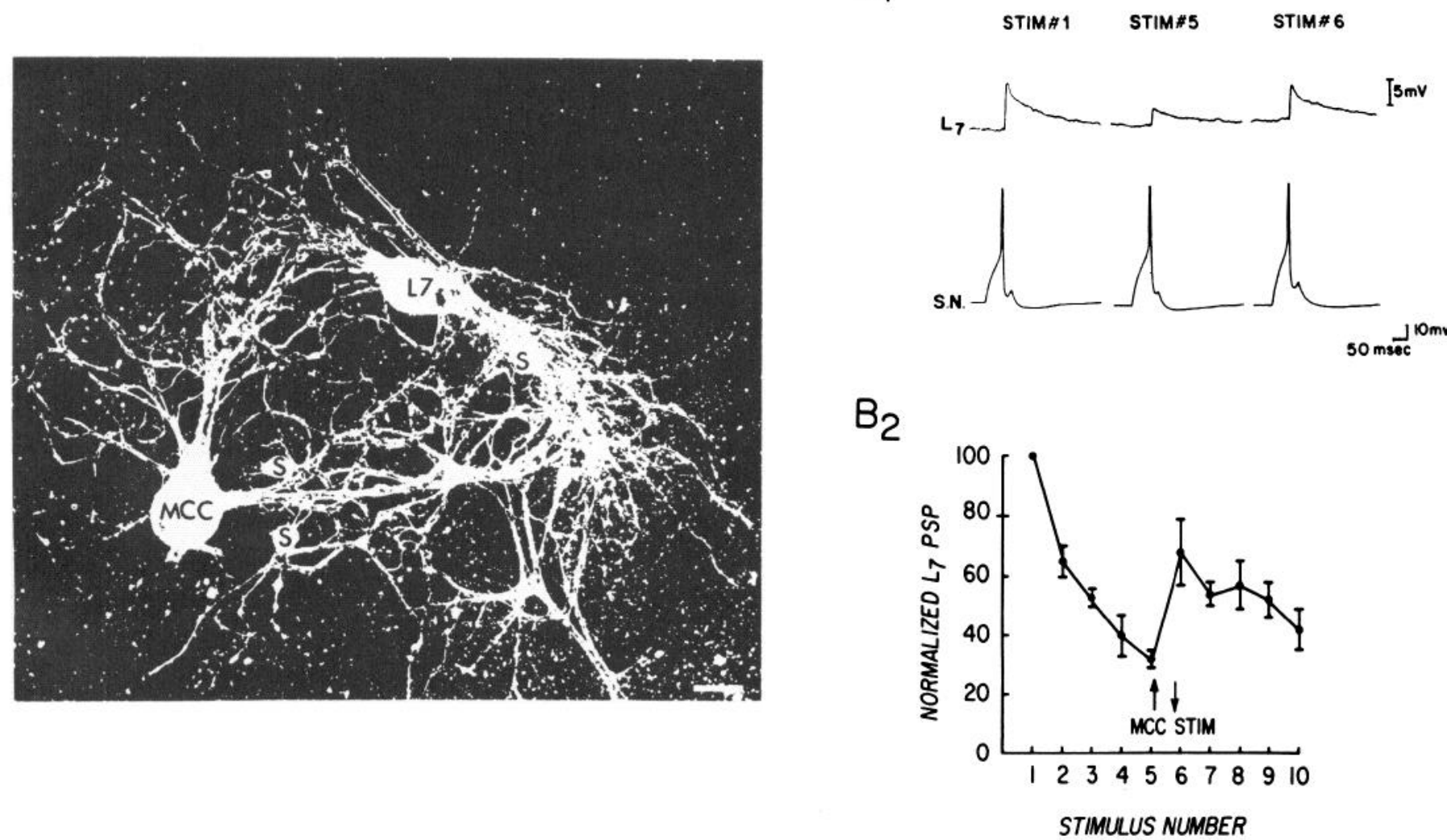

Figure 4. A, Elementary three-cell gill withdrawal neural circuit in dissociated cell culture after 5 d. $S$, LE sensory cell; $L 7$, motor cell; $M C C$, metacerebral cell. Calibration, $100 \mu \mathrm{m}$. B. Electrophysiology of the three-cell circuit. Sensory, motor, and metacerebral cells were simultaneously impaled with single-barreled electrodes. The motor cell was hyperpolarized $50 \mathrm{mV}$ below rest. The sensory neuron was then fired with a brief depolarizing current pulse once every $20 \mathrm{sec}$. Between the fifth and sixth stimuli, the MCC was fired with a long depolarizing current step, causing it to fire three to five spikes/sec for $15 \mathrm{sec}$. The records in $B_{i}$, show, first, the initial PSP, then the fifth PSP, displaying the magnitude of homosynaptic depression, followed by the PSP after MCC firing, showing maximum facilitation. The graph in $B_{2}$ summarizes the results of five experiments, normalized by adjusting the initial PSP of each LE-L7 connection to unity. Points are means and SEM.

the MCC may act in a manner equivalent to the exogenous application of 5-HT.

During Aplysia development, homosynaptic depression is well established before the emergence of heterosynaptic facilitation (Rayport and Camardo, 1984). In culture, cells reestablish connections with mature plastic properties within $5 \mathrm{~d}$. Thus, sequential recordings during the first few days may permit examination of synapse formation, as well as the acquisition of synaptic plasticities mediating habituation and sensitization. Such explorations of the developing gill withdrawal circuit in culture may begin to indicate whether developmental processes underlying synapse formation are carried over to the adult in mediating synaptic plasticity and learning.

\section{References}

Abrams, T. A., V. F. Castellucci, J. S. Camardo, E. R. Kandel, and P. E. Lloyd (1984) Two endogenous neuropeptides modulate the gill and siphon withdrawal reflex in Aplysia by means of presynaptic facilitation involving cyclic AMP-dependent closure of a serotoninsensitive K channel. Proc. Natl. Acad. Sci. USA 81: 7956-7960.

Bailey, C. H., E. B. Thompson, V. F. Castellucci, and E. R. Kandel (1979) Ultrastructure of the synapses of sensory neurons that mediate the gill-withdrawal reflex in Aplysia. J. Neurocytol. 8: 415-444.

Bailey, C. H., R. D. Hawkins, M. C. Chen, and E. R. Kandel (1981) Interneurons involved in mediation and modulation of gill-withdrawal reflex in Aplysia. IV. Morphological basis of presynaptic facilitation. J. Neurophysiol. 45: 340-360.

Belardetti, F., S. Schacher, E. R. Kandel, and S. A. Siegelbaum (1985) Serotonin produces a decreased conductance EPSP and broadening of the action potential in growth cones of Aplysia neurons. Soc. Neurosci. Abstr.

Brunelli, M., V. F. Castellucci, and E. R. Kandel (1976) Synaptic facilitation and behavioral sensitization in Aplysia: Possible role of serotonin and cyclic AMP. Science 194: 1178-1181.

Camardo, J., E. Proshansky, and S. Schacher (1983) Identified Aplysia neurons form specific chemical synapses in culture. J. Neurosci. 3: 2814-2820.

Carew, T. J., R. D. Hawkins, and E. R. Kandel (1983) Differential classical conditioning of a defensive withdrawal reflex in Aplysia californica. Science 219: 397-400.

Castellucci, V. F., and E. R. Kandel (1974) A quantal analysis of the synaptic depression underlying habituation of the gill-withdrawal reflex in Aplysia. Proc. Natl. Acad. Sci. USA 71: 5004-5008.

Castellucci, V. F., and E. R. Kandel (1976) Presynaptic facilitation as a mechanism for behavioral sensitization in Aplysia. Science 194: 1176-1178.

Hawkins, R. D., V. F. Castellucci, and E. R. Kandel (1981a) Interneurons involved in mediation and modulation of the gill-withdrawal reflex in Aplysia. I. Identification and characterization. J. Neurophysiol. 45: 304-314.

Hawkins, R. D., V. F. Castellucci, and E. R. Kandel (1981b) Interneurons involved in mediation and modulation of the gill-withdrawal reflex in Aplysia. II. Identified neurons produce heterosynaptic facilitation contributing to behavioral sensitization. J. Neurophysiol. 45: 315-326.

Hawkins, R. D., T. W. Abrams, T. J. Carew, and E. R. Kandel (1983) A cellular mechanism of classical conditioning in Aplysia: Activitydependent amplification of presynaptic facilitation. Science 219:400405.

Hochner, B., S. Schacher, M. Klein, and E. R. Kandel (1985) Pre- 
synaptic facilitation in Aplysia sensory neurons: A process independent of $\mathrm{K}^{+}$current modulation becomes important when transmitter release is depressed. Soc. Neurosci. Abstr.

Hume, R. I., L. W. Role, and G. D. Fischbach (1983) Acetylcholine release from growth cones detected with patches of acetylcholine receptor-rich membranes. Nature 305: 632-634.

Kandel, E. R. (1979) Cellular insights into behavior and learning. In The Harvey Lectures, Ser. 73, D. Marcus, ed., pp. 19-92, Academic, New York.

Kandel, E. R., and J. H. Schwartz (1982) Molecular biology of an elementary form of learning: Modulation of transmitter release by cyclic AMP. Science 218: 433-443.

Klein, M., and E. R. Kandel (1978) Presynaptic modulation of voltagedependent $\mathrm{Ca}^{2+}$ current: Mechanism for behavioral sensitization in Aplysia californica. Proc. Natl. Acad. Sci. USA 75: 3512-3516.

Klein, M., E. Shapiro, and E. R. Kandel (1980) Synaptic plasticity and the modulation of the $\mathrm{Ca}^{++}$current. J. Exp. Biol. 89: 117-157.

Klein, M., J. S. Camardo, and E. R. Kandel (1982) Serotonin modulates a specific potassium current in the sensory neurons that show presynaptic facilitation in Aplysia. Proc. Natl. Acad. Sci. USA 79: 5713-5717.

Kriegstein, A. R. (1977) Development of the nervous system of Aplysia californica. Proc. Natl. Acad. Sci. USA 74: 375-378.

Kriegstein, A. R., V. F. Castellucci, and E. R. Kandel (1974) Metamorphosis of Aplysia californica in laboratory culture. Proc. Natl. Acad. Sci. USA 71: 3654-3658.

Montarolo, P. G., V. F. Castellucci, P. Goelet, E. R. Kandel, and S. Schacher (1985) Long-term facilitation of the monosynaptic connection between sensory neurons and motor neurons of the gill withdrawal reflex in Aplysia in dissociated cell culture. Soc. Neurosci. Abstr.
Rayport, S. G., and J. S. Camardo (1984) Development of synaptic plasticity mediating habituation and sensitization in Aplysia. J. Neurosci. 4: $2528-2532$.

Rayport, S. G., and S. Schacher (1984) Elementary neural circuit of Aplysia gill-withdrawal reflex reconstituted in cell culture shows homosynaptic depression and 5HT-induced facilitation. Soc. Neurosci. Abstr. 10:923.

Schacher, S. (1985) Differential synapse formation and neurite outgrowth at two branches of the metacerebral cell of Aplysia in dissociated cell culture. J. Neurosci. 5: 2028-2034.

Schacher, S., and E. Proshansky (1983) Neurite regeneration by Aplysia neurons in dissociated cell culture: Modulation by Aplysia hemolymph and the presence of the initial axonal segment. J. Neurosci. 3: 2403-2413.

Schacher, S., S. G. Rayport, and R. T. Ambron (1985) Giant Aplysia neuron R2 reliably forms chemical connections in vitro. J. Neurosci. 5: 2851-2856.

Weiss, K. R., J. L. Cohen, and I. Kupfermann (1978) Modulatory control of buccal musculature by a serotonergic neuron in Aplysia. J. Neurophysiol. 41: 181-203.

Weiss, K. R., D. E. Mandelbaum, M. Schonberg, and I. Kupfermann (1979) Modulation of buccal muscle contractility by serotonergic metacerebral cells in Aplysia: Evidence for a role in cyclic AMP. J. Neurophysiol. 42: 791-803.

Weiss, K. R., S. Schacher, I. Kupfermann, and P. E. Lloyd (1985) Calcium-dependent release of neuropeptides (the SCPs) evoked by intracellular stimulation of single identified Aplysia neurons in cell culture. Soc. Neurosci. Abstr. 11: 482.

Young, S. H., and M. Poo (1983) Spontaneous release of transmitter from growth cones of embryonic neurons. Nature 305: 634-637. 